Article

\title{
Edible Environmental Enrichments in Littered Housing Systems: Do Their Effects on Integument Condition Differ Between Commercial Laying Hen Strains?
}

\author{
Ruben Schreiter ${ }^{1, *}$, Klaus Damme ${ }^{2}$ and Markus Freick ${ }^{1,3}$ (D) \\ 1 ZAFT e.V. Centre for Applied Research and Technology, D-01069 Dresden, Germany; \\ markus.freick@htw-dresden.de \\ 2 Bavarian State Farms, Research and Education Center for Poultry, D-97318 Kitzingen, Germany; \\ klaus.damme@baysg.bayern.de \\ 3 Faculty of Agriculture/Environment/Chemistry, HTW Dresden-University of Applied Sciences, \\ D-01326 Dresden, Germany \\ * Correspondence: ruben.schreiter@htw-dresden.de; Tel.: +49-73-734-51-13
}

Received: 3 December 2020; Accepted: 16 December 2020; Published: 18 December 2020

Simple Summary: Feather pecking can occur in laying hens. It is considered a behavioral disorder and can be triggered by a variety of factors. Feather pecking leads to plumage damage, which is detrimental to the welfare and performance of the animals. The behavior of allopecking is assigned to foraging and exploration behavior. Therefore, a possible approach to reduce feather pecking is to provide manipulatable, edible objects to direct the hens' pecking to these substrates. Previous studies could not clearly answer the question of the effects of providing such environmental enrichment materials on plumage condition and performance. In order to clarify this question and investigate possible differences between different breeding lines, 4000 pullets were kept during rearing and 2808 hens were kept during the laying period with or without additional enrichment materials (pecking stones and alfalfa bales). The results showed that the effect of enrichment materials on plumage condition and also on pecking injuries of the skin differed between genetic strains. Therefore, the recommendations for the use of enrichment materials should be revised and specified for the hybrid lines.

\begin{abstract}
The aim of this study was to investigate the effect of additional enrichment materials (EMs; pecking stones and alfalfa bales) on the occurrence of plumage damage, skin injuries, and toe injuries, with an emphasis on the possible differences between commercial hybrid strains of laying hens. During rearing (weeks 1-18, 16 compartments, 4000 pullets) and laying periods (weeks 21-72, 24 compartments, 2808 hens) in a littered housing system, EMs were permanently provided to the study groups (EXP), while control groups (CON) did not receive additional EM. In a two-factorial study design (two groups with four strains) with 351 hens per variant, the brown egg-laying Lohmann Brown classic (LB) and Bovans Brown (BB) strains as well as the white egg-laying Lohmann Selected Leghorn classic (LSL) and Dekalb White (DW) strains were investigated. Compared to the CON, the EXP showed reduced body mass during rearing $(p<0.001)$ and reduced albumen consistency in the laying period $(p<0.001)$. Regarding integument condition, the LSL in the EXP showed more toe injuries than in the CON $(p=0.018)$. Remarkably, genotype-environment interactions between strains and groups were evident $(p<0.001)$. In groups with an EM supply, plumage damage decreased in LB $(p \leq 0.033)$ and LSL $(p \leq 0.005)$ but increased in BB $(p \leq 0.003)$. Moreover, there were fewer skin injuries in LSL $(p=0.001)$ but more in BB $(p=0.001)$ in groups with access to EM. In view of the diverging effects between strains, future practical recommendations for laying hen husbandry should be strain-specific.
\end{abstract}


Keywords: egg production; animal welfare; layers; pullets; feather pecking; genotype-environment interaction

\section{Introduction}

Feather pecking and cannibalism are behavioral disorders that can occur in laying hens in all housing systems [1]. They result in serious problems with regard to animal welfare but also in negative effects on the performance of the flocks and the economic success of laying hen farmers [2-6]. In feather pecking, a distinction can be made between gentle feather pecking, which does not lead to plumage loss, and severe feather pecking (SFP) [7]. SFP leads to plumage damage and increases the risk of pecking injuries to the exposed skin [8]. Pecking on the skin and underlying tissues of conspecifics is designated as cannibalism and, as with feather pecking, is not an aggressively motivated behavior $[7,9]$.

If SFP and/or cannibalism occur in flocks, they are relevant for animal welfare, since extensive feather loss significantly restricts the well-being of the hens [5] and the pecked animals feel pain [10]. Toe pecking, which occurs especially in white egg layers, can lead to considerable pain, injuries, loss of toe limbs, and animal losses [11,12]. During this process, hens often peck their own toes until injuries occur [13]. Although beak trimming at chick age cannot prevent allopecking behaviors, it can significantly reduce plumage damage, injuries, and increased animal losses [14-16]. Therefore, with the abandonment of beak trimming in several European countries (e.g., Austria, Norway, Germany), the risk of integument damage and animal losses has increased $[17,18]$. Consequently, efforts to counteract the causes of allopecking behaviors must be intensified. Key measures for laying hen farmers include improving the adaption period after transfer to the laying stable, increasing the structuring of the housing environment, using flicker-free lighting, optimizing the feed composition, and reducing the level of harmful gases in the stable [9].

Genetics, feeding, housing, and management are regarded as central complexes in the multifactorial causal structure of SFP and cannibalism [19-22]. Since SFP is regarded as a misdirection of foraging and feed intake behavior $[23,24]$, the supply of manipulatable materials to the birds is of high relevance [5]. There is no consistent knowledge of the effect of additional enrichment materials (EMs) on the prevalence of SFP or plumage damage in laying hens kept in littered housing systems (reviewed by [25]). With the addition of cereals to the litter during rearing, [26] observed less feather pecking in the laying period. Sand and peat during rearing as well as straw provided in baskets during the laying period could reduce plumage damage in laying hens [27]. Such an effect was achieved in [28] by enriching the rearing stable with structural elements and novel objects. In pullets, the use of strings or pecking stones and alfalfa bales could reduce the occurrence of feather pecking [6,29]. Moreover, less plumage damage was observed due to the additional supply of maize silage, pea/barley silage, and carrots [30], as well as pecking stones and alfalfa bales [31]. On the other hand, other authors did not observe the positive effects of these EMs [16,32-34]. However, none of these studies examined different genetic strains of white egg and brown egg-laying hens in parallel. Therefore, knowledge of possible genotype-environment interactions (GEIs) in the provision of EMs regarding SFP and cannibalism is lacking. The existence of GEIs in laying hens has been demonstrated between strains and housing systems regarding performance characteristics or feeding behavior [35-38]. Brown egg layers in floor housing showed a lower feed intake than in small-group housing, whereas no differences in feed intake between the housing types were found in white egg layers [38]. The laying performance of different hybrid strains varied between different test environments as a result of GEI [35-37].

The aim of this study was to examine the effect of EM on the integument condition in laying hens and to identify possible differences between strains. The following hypotheses were generated: (1) by providing EM, the prevalence of severe plumage and skin damage can be reduced in week 72 (i.e., at the end of the laying period), and (2) the effects of EM supply on integument condition differ between the strains. 


\section{Materials and Methods}

The study was conducted at the Bavarian State Research Center for Agriculture in the Department of Applied Research and Education in Poultry (Kitzingen, Germany) on non-beak trimmed pullets and laying hens from January 2019 to May 2020. In a single run, the effect of additional EM on the prevalence of integumentary damage, animal development, and laying performance was investigated in different hybrid strains.

\subsection{Housing and Management}

The rearing stable was equipped with a two-floored aviary system (Natura Filia, Big Dutchman AG, Vechta-Calveslage, Germany) and divided into 16 identical compartments (12.9 $\mathrm{m}^{2}$ of floor area each, including $6.6 \mathrm{~m}^{2}$ grids and $6.3 \mathrm{~m}^{2}$ litter, and $19.4 \mathrm{hens} / \mathrm{m}^{2}$ usable area, equipped with perches, a flat chain feeding system and nipple drinkers). On the first day of life, 250 chicks per compartment were placed in the lower aviary level. On day 8 , half of the chicks per compartment were transferred to the upper aviary level. Prior to housing, $80 \%$ of the grid area was covered with chick paper (roll corrugated board, REKA Wellpappenwerke, Kitzingen, Germany), which was removed at the end of week 5. Chick starter feed (see below) was provided on the chick paper from day 1 to 8 to encourage the chicks to take up feed. On day 35, the aviary segments were opened to allow access to the floor area, which was littered with softwood shavings (Premiumspan ${ }^{\circledR}$, Hobelspanverarbeitung GmbH, Dittersdorf, Germany). To maintain an attractive, loose litter, the area was re-littered with softwood shavings in identical quantities in each compartment at two-week intervals. The lighting of the barn was provided by Light-Emitting Diode (LED) tubes (FlexLED, Big Dutchman AG, Vechta-Calveslage, Germany), which were installed in the longitudinal direction of the barn centrally above each scratching area and also in the lower level of the aviary.

In week 19, the pullets were transferred to a laying stable with 24 compartments $\left(15.6 \mathrm{~m}^{2}\right.$ of floor area each; 7.5 hens $/ \mathrm{m}^{2}$ usable area). Each compartment housed 117 hens (hens housed, $\mathrm{HH}$ ) and was equipped with an automatic round trough feeder (Big Dutchman AG, Vechta-Calveslage, Germany), a nipple drinker line (Big Dutchman AG, Vechta-Calveslage, Germany), a double-storey family nest with Astroturf mats (VencoTec $\mathrm{GmbH}$, Holzheim, Germany, each storey $3.3 \times 0.5 \mathrm{~m}$ ) and perches (self-made from wood, rectangular cross-section $4 \times 5 \mathrm{~cm}$, total length $14.8 \mathrm{~m}$ ). One third of the floor area was littered with softwood shavings (Premiumspan ${ }^{\circledR}$, Hobelspanverarbeitung GmbH, Dittersdorf, Germany), while the remaining two thirds consisted of perforated flooring (plastic grids, Big Dutchman AG, Vechta-Calveslage, Germany) with an underlying manure belt (Big Dutchman AG, Vechta-Calveslage, Germany). At four-week intervals, the litter was removed from the compartments and replaced by new softwood shavings (see above). The lighting of the laying stable was provided by LED lamps (LED lamp, Big Dutchman AG, Vechta-Calveslage, Germany), which were located in each compartment above the littered area.

For demand-oriented feeding during the rearing period, a three-phase feeding program (from Deutsche Tiernahrung Cremer GmbH \& Co. KG, Regensburg, Germany) with complete chick feed (weeks 1-10, Bonimal GK KAM, Deutsche Tiernahrung Cremer GmbH \& Co. KG, Regensburg, Germany) and complete pullet feed (weeks 11-18, Bonimal GK JAM, Deutsche Tiernahrung Cremer $\mathrm{GmbH} \& \mathrm{Co} . \mathrm{KG}$, Regensburg, Germany) in the rearing stable and a pre-laying diet after moving to the laying stable (weeks 19-20, Bonimal GK Vorlegemehl, Regensburg, Germany) was provided. Then, birds were fed complete feeds for laying hens (from Deutsche Tiernahrung Cremer GmbH \& Co. KG, Regensburg, Germany) designed for phase I (weeks 21-60, Bonimal GK LAM 40, Regensburg, Germany) or phase II (weeks 61-72, Bonimal GK LAM 44, Regensburg, Germany). The nutrient and active substance levels were based on current recommendations [39]. Feed and drinking water were available ad libitum to the animals during the rearing and laying periods. All the feeds of the study had a mashed structure.

A regulated step-down-step-up light program, based on the current management recommendations [39], was used for the targeted control of animal development and laying maturity. 
The window surfaces in the rearing and laying stables were completely darkened. The average lighting intensity at animal height in the feeding and littered area was 35 lux in weeks 1-3 and 20 lux from week 4 onwards. In order to ensure stable animal health and to reduce animal losses, a vaccination program appropriate for the stock, region, and intended use was undertaken following the recommendations of [39].

\subsection{Animals, Study Design, and Data Collection}

The animals were kept in accordance with the legal measures of the EU (Council Directive 1999/74/EC, minimum standards for the protection of laying hens) [40] and Germany (Animal Welfare Act; Animal Protection Keeping of Production Animals Order) [41,42]. In particular, the principles and specific guidelines of the Guide for the Care and Use of Agricultural Animals in Research and Teaching [43] were implemented. In accordance with Directive 2010/63/EU of the European Parliament and of the Council on the protection of animals used for scientific purposes [44], no invasive treatment of the hens was performed.

For this study, 1000 one-day-old chicks each of the commercial brown egg-layer hybrid strains Lohmann Brown classic (LB; Lohmann Tierzucht, Cuxhaven, Germany; purchased from LSL Rhein Main hatchery, Dieburg, Germany) and Bovans Brown (BB; Hendrix Genetics, Boxmeer, The Netherlands; purchased from Het Anker BV hatchery, Ochten, The Netherlands) as well as 1000 one-day-old chicks each of the commercial white egg-layer hybrid strains Lohmann Selected Leghorn classic (LSL; Lohmann Tierzucht, Cuxhaven, Germany; purchased from LSL Rhein Main hatchery, Dieburg, Germany) and Dekalb White (DW; Hendrix Genetics, Boxmeer, The Netherlands; purchased from Het Anker BV hatchery, Ochten, The Netherlands) were housed in the rearing stable with 250 chicks per compartment. In week 19, the hens were transferred to a laying stable. Only hens from the same rearing compartment were housed in one laying compartment. For each of the four strains under investigation, 702 hens were placed in the 24 compartments (i.e., 117 hens per compartment). The assignment to the compartments was alternated for the four hybrid strains and blocked for the two study groups (see below) (Figure 1A). For each variant (i.e., four strains and two groups resulting in eight variants), two compartments were available for rearing and three for the laying period.

Regarding the supply of edible enrichment materials in addition to the litter, birds of each strain were divided into two different groups. In the control group (CON), no EM was supplied during the rearing and laying periods apart from the chick paper and litter. In the experimental group $(\mathrm{EXP})$, additional EMs were available to the birds from the first day of life. For that purpose, pecking stones (Vilolith ${ }^{\circledR}$ medium, Deutsche Vilomix Tierernährung GmbH, Neuenkirchen-Vörden, Germany) and hard-pressed alfalfa bales (Einstreuprofi, Seelingstädt, Germany) were supplied. The EMs were provided ad libitum and were replaced in the compartment shortly before complete consumption. Pecking stones and alflafa bales were placed centrally in the aviary compartment (weeks 1-5) and in the littered area (from week 6) next to each other. From week 8 onwards, EMs were offered in the littered area only. In the phase with closed aviary segments (weeks 1-5), pecking stones and alfalfa blocks were placed in flat feed trays (Futterteller, Siepmann GmbH, Herdecke, Germany). Two pecking stones and four alfalfa bales were permanently available to the animals in each compartment.

In this observational longitudinal study, the characteristics of integument condition and body mass, laying performance, egg quality, mortality, feed consumption, and EM consumption were assessed (Figure 1B). 

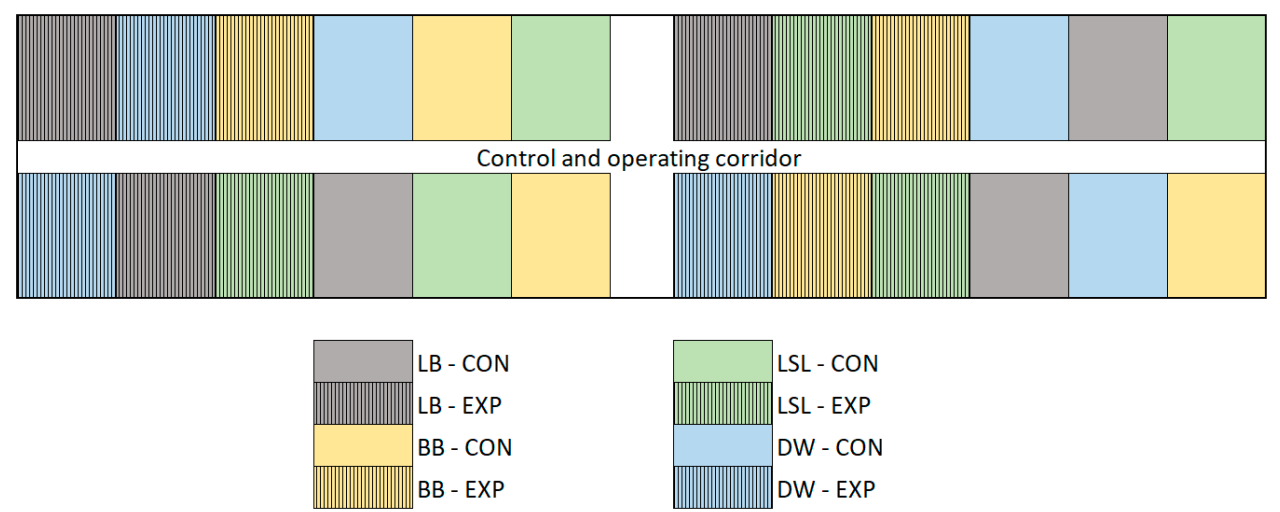

(A)

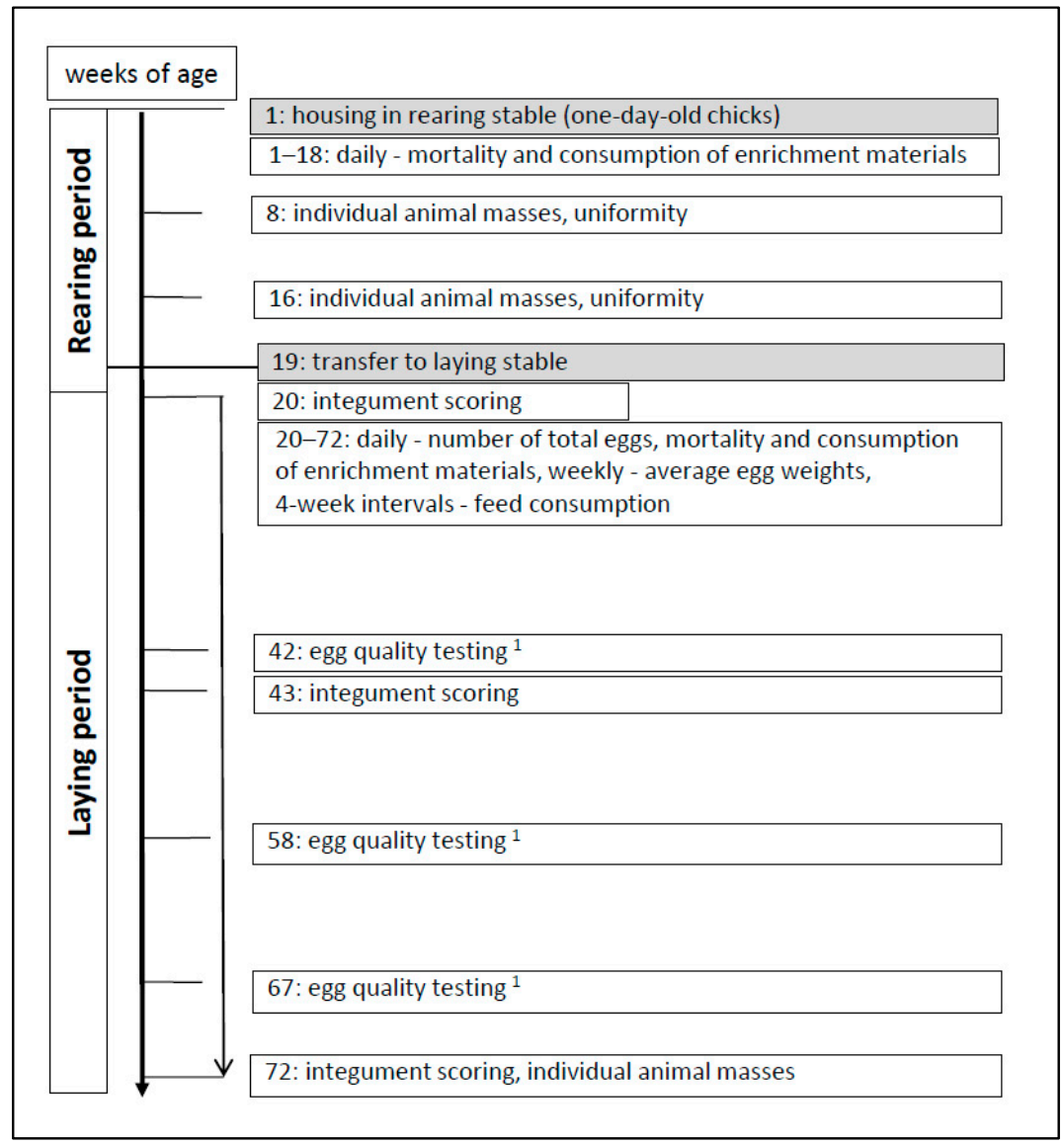

(B)

Figure 1. Study design: (A) Assignment of the four hybrid strains and two study groups to the compartments in the laying stable. (B) Times of scorings and data collection. Grey fields represent housing events. LB (CON_control group)—Lohmann Brown classic without supply of enrichment materials; LB (EXP_experimental group)—Lohmann Brown classic with supply of enrichment materials; BB (CON)-Bovans Brown without supply of enrichment materials; BB (EXP)—Bovans Brown with supply of enrichment materials; LSL (CON)—Lohmann Selected Leghorn classic without supply of enrichment materials; LSL (EXP)_Lohmann Selected Leghorn classic with supply of enrichment materials; DW (CON)—Dekalb White without supply of enrichment materials; DW (EXP)—Dekalb White with supply of enrichment materials. ${ }^{1}$-individual egg weights, breaking strength of the eggshells, and albumen consistency. 
For the indirect determination of the occurrence of SFP and cannibalism, a scoring of the integument was performed in weeks 20, 43, and 72. These dates were chosen to depict the most important stages of the laying period regarding plumage condition-i.e., laying maturity (week 20), peak of egg mass production (week 43) and the final of the laying period (week 72). For integument scoring, individual birds were regarded as experimental units, and the required sample size was calculated from our preliminary investigations (data not shown) using a web-based tool [45]. In order to prove differences of $20 \%$ in the proportion of birds with integument damages with a statistical power of 0.80 and a significance level set at $\alpha=0.05$, a sample size of a minimum of 72 birds per variant was necessary. At each observation date, a subset of 25 randomly selected hens per compartment (i.e., $n=75$ per variant) was therefore scored. The scoring was based on the Welfare Quality ${ }^{\circledR}$ protocol [46] modified by [47] for the integument traits of plumage damage, skin injuries, toe injuries, and foot pad condition. For plumage scoring, the following scores were used: $0=$ intact plumage with featherless areas up to $1 \mathrm{~cm} ; 1=$ slight plumage damage with featherless areas $>1$ to $5 \mathrm{~cm} ; 2=$ severe plumage damage with featherless areas $>5 \mathrm{~cm}$. Skin lesions were classified by score $0=$ intact skin; score $1=$ small pecking lesions up to $1 \mathrm{~cm}$ in diameter; score $2=$ lesions and/or wounds larger than $1 \mathrm{~cm}$ at the largest diameter.

The scoring of the plumage was differentiated according to the back, belly (including cloacal region and ventral rump) and dorsal neck. In addition to the three individual scores, a total plumage score was calculated on the individual animal level by adding the individual scores. The feathers of the front of the neck and the breast were not included in the scoring, as feather damage in these areas due to mechanical stress from the feeding trough does not provide strong evidence for SFP [8]. For the assessment of skin injuries, all the feathered body regions were relevant. For the evaluation of toe injuries, the toes with the most severe damage were decisive for the assigned score. Integument scoring was always performed by the same observer who had previously completed training in the application of this scoring system with 3500 hens. The investigator was blinded for the study group.

During the rearing period (weeks 1-18), the feed consumption was determined in each compartment at the end of the 14-day period by recording the quantity consumed using a feeding computer (Fancom 743, Fancom, Panningen, The Netherlands) and a manual back weighing (Defender 3000 scale). Feed consumption was determined by continuous feed and back weighing (Defender 3000 scale, Ohaus, Parsippany, NJ, USA) in four-week intervals during the laying period. Each pecking stone and alfalfa bale of each compartment was weighed during rearing and the laying period (DE6 K2N scale, Kern, Balingen, Germany). Animal losses were recorded daily. Dead hens with bloody skin injuries (diameter $\geq 1 \mathrm{~cm}$ ) or skin injuries and bloody surrounding plumage were classified as mortality due to skin cannibalism, and those with toe injuries as mortality due to toe cannibalism. In weeks 8 and 16, the individual animal masses were determined using the Flexscale (Big Dutchman AG, Vechta-Calveslage, Germany) by weighing 50 animals per compartment (two compartments per variant, $n=100$ animals). In week 72 , all remaining hens were weighed $(n=2621)$. At the same time, the uniformity for each compartment was calculated on the basis of these individual animal masses. The uniformity indicates the proportion of animals weighed in a sample with respect to a body mass that lies within $\pm 10 \%$ of the arithmetic mean of the sample [48] During the laying period, the number of total eggs for each compartment was recorded daily. The average egg weight was determined weekly by weighing with a digital scale (Kern DE6 K2N, Kern, Balingen, Germany) all individual eggs of one daily clutch of each compartment. The laying performance per average hen and per hen housed was calculated according to [49]. Egg quality traits were assessed in weeks 42, 58, and 67 in 15 randomly selected eggs per compartment in the same way as reported by [49] for the egg quality assessments in laying hen performance tests. The egg weight (Navigator NV1101 digital scale, Ohaus, Parsippany, NJ, USA), breaking strength of the egg shells (FEST V2.0 egg shell tester, Futura, Lohne, Germany), and albumen height (1/A 2001 albumen altimeter, Futura, Lohne, Germany) were measured. Based on the egg weight and albumen height, the Haugh units (HU) for characterizing albumen consistency were calculated [50]. 


\subsection{Statistical Analyses}

Microsoft Excel ${ }^{\circledR}$ (Version 2013, Microsoft Corporation, Redmond, WA, USA) was used for the data collection and processing and the creation of selected diagrams. In the figures illustrating the plumage condition (see the Results section), the presented proportion per score corresponds to the arithmetic mean of the three scored plumage regions. For further descriptive and inferential statistical analyses, the Standard SAS program package (Version 9.4., SAS Institute Inc., Cary, NC, USA) and the IBM SPSS Statistics program (Version 23, SPSS Inc., Chicago, IL, USA) were used. The normal distribution of the residuals was tested using the Kolmogorov-Smirnov test [51].

For normally distributed data (i.e., egg number per hen housed, egg number per average hen, egg mass per hen housed, egg mass per average hen, egg weight, uniformity, feed, and EM consumption and feed conversion), two-factorial ANOVA linear models were calculated [52] with the fixed effects of strains, groups and the strain-group interaction. For post-hoc pairwise comparisons, the GT2 (Generalized Tukey 2) test according to Hochberg was used [51,53]. To control for the false discovery rate due to multiple testing, the Benjamini-Hochberg procedure was employed [54]. For the analysis of individual animal body masses during the rearing period and egg quality traits in the laying period (albumen consistency and breaking strength), ANOVA linear models with groups and strains as between-subject effects and age as a within-subject effect was used, due to repeated measurements [53].

To evaluate the effects of the fixed factors of strains, hybrid types (i.e., white egg layers vs. brown egg layers), study groups, and their interactions on the ordinally scaled integument characteristics (i.e., total plumage score, skin injuries, and toe injuries) as well as on the metrically scaled traits without normal distribution (cumulative mortality, mortality due to skin or toe cannibalism), non-parametric tests were used. For differences between the strains, the Kruskal-Wallis test was applied. As a test for differences between the enrichment groups or in the presence of significant differences between the strains, a pairwise comparison was performed using the Mann-Whitney $U$ test [52]. A correction for multiple testing was not implemented, since-in particular with regard to the integument traits-the study was considered as an explorative approach and the univariate analyses were performed in preparation for the regression models, as described below [54].

Multiple logistic regression models with total plumage score and skin injuries (i.e., the main outcomes of the study) as dependent variables and strains, groups, ages, compartment, and strain-group interactions as independent variables were fitted to the data using binary logistic regression (BLR) models [55]. All the independent variables were forced into the models (with the inclusion method). Multiple logistic rather than ordinal regression models were used because some scores were occupied by only very few observations. For multiple logistic regressions, the ordinal data scaling (as defined by $[46,47]$ ) was transformed into a nominal scaling (the total plumage score was 0 for scores of 0 and 1 and 1 for a score of $\geq 2$; the skin injury score was 0 for a score of 0 and 1 for a score of $\geq 1$ ). The absence of multicollinearity was ensured by the calculation of Pearson's correlation coefficient and by a collinearity diagnosis with a variance inflation factor and condition index $[56,57]$. Nagelkerke's $\mathrm{R}^{2}$ values, which give an indication of the extent of the variation of the dependent variables explained by the model, were calculated. Nagelkerke's $R^{2}$ values $\geq 0.5$ were considered as very good and values in the range $0.4 \leq R^{2}<0.5$ as good [58]. In all of the described inferential statistical analyses, differences were considered statistically significant for $p \leq 0.05$ and tended to be significant if $0.05<p \leq 0.1$.

\section{Results}

\subsection{Integument Condition}

The univariate analyses revealed strain effects on plumage condition on all scoring dates (i.e., weeks 20, 43 and 72; $p<0.001$ ) for the occurrence of skin injuries in weeks $43(p<0.001)$ and $72(p=0.005)$, and toe injuries in weeks $43(p<0.001)$ and $72(p<0.001)$ (data not shown). Significant effects of the hybrid type on the plumage condition could be demonstrated in weeks 20, 43 and $72(p<0.001$ each) with less plumage damage in the white egg layers (week 20: $98.6 \%$ score 0 , 
1.3\% score 1 and $0.1 \%$ score 2; week 43 : $76.6 \%$ score $0,13.7 \%$ score 1 and $9.8 \%$ score 2 ; week 72 : $19.8 \%$ score $0,42.6 \%$ score 1 and $37.7 \%$ score 2 ) in comparison to the brown egg layers (week 20 : $96.0 \%$ score $0,3.4 \%$ score 1 and $0.6 \%$ score 2 ; week $43: 55.7 \%$ score $0,23.9 \%$ score 1 and 20.4\% score 2; week 72: $13.3 \%$ score $0,35.2 \%$ score 1 and $51.5 \%$ score 2 ). An effect of the hybrid type regarding the skin lesions was found in week 72 ( $p<0.001$; brown egg layers: $66.0 \%$ score $0,22.0 \%$ score 1 and $12.0 \%$ score 2 ; white egg layers: $77.0 \%$ score $0,21.7 \%$ score 1 and $1.3 \%$ score 2 ), but not in weeks 20 $(p=1.000)$ and $43(p=0.602)$. With the exception of $0.3 \%$ moderate toe injuries in week 43 , all of the brown egg-layer hens had intact toes, while the white egg layers showed significantly more toe injuries in weeks $43(p<0.001 ; 91.7 \%$ score $0,5.3 \%$ score 1 and $3.0 \%$ score 2$)$ and $72(p<0.001 ; 91.0 \%$ score 0 , $0.7 \%$ score 1 and $8.3 \%$ score 2 ).

Hens of all strains and groups already showed the first plumage damages - to a small extent-in week 20. At that time, the plumage loss in LB hens in the EXP groups was lower than in the CON (CON: 91.6\% score $0,7.1 \%$ score $1,1.3 \%$ score 2 ; EXP: $94.7 \%$ score $0,4.0 \%$ score $1,1.3 \%$ score 2$)(p=0.033)$, while it tended to be higher in BB in the EXP (CON: $100.0 \%$ score 0 ; EXP: $96.0 \%$ score $0,4.0 \%$ score 1 ) $(p=0.087)$. No differences in plumage condition between the CON and EXP could be identified for LSL ( $p=0.992)$ and DW ( $p=0.188)$. Diverging strain effects were also evident in week 43 (Figure 2A). The supply of EM reduced plumage damage in LB and LSL but increased plumage loss in BB and DW. With the exception of DW, these effects were confirmed in week 72 (Figure 2B). At that time, plumage damage in DW was more pronounced in CON. All the birds showed an intact skin in week 20. However, first moderate injuries were observed in week 43 in all strains and groups, while severe skin injuries occurred in week 72 in LB (CON and EXP: 16.0\% each), BB (CON: 9.3\%, EXP: 6.7\%) and LSL (CON: $4.0 \%$, EXP: 1.3\%). Within the strains, the prevalence of skin lesions was lower in BB in the CON groups in week 43 and in LSL in the EXP groups in week 72 (Figure 3).

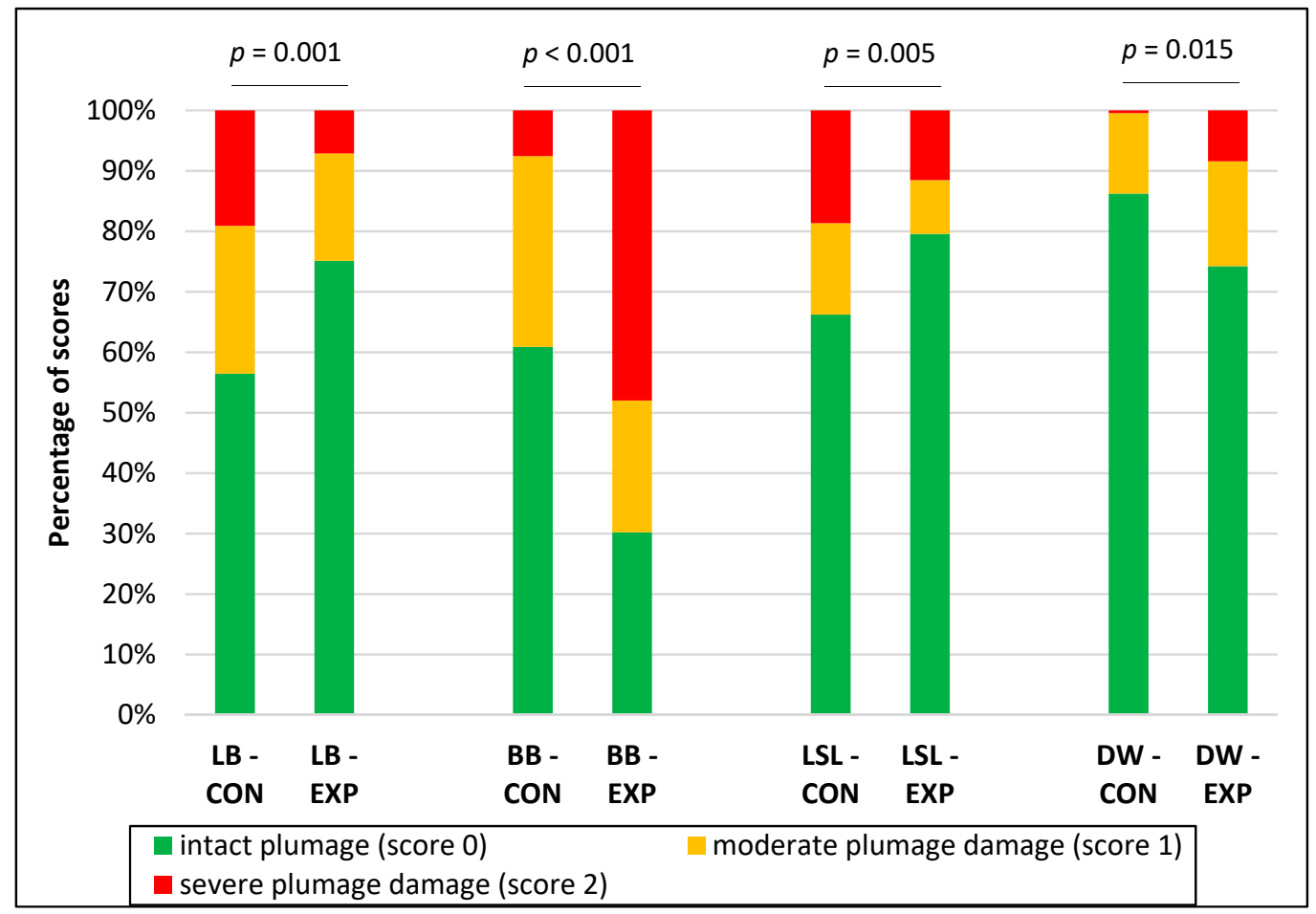

(A)

Figure 2. Cont. 


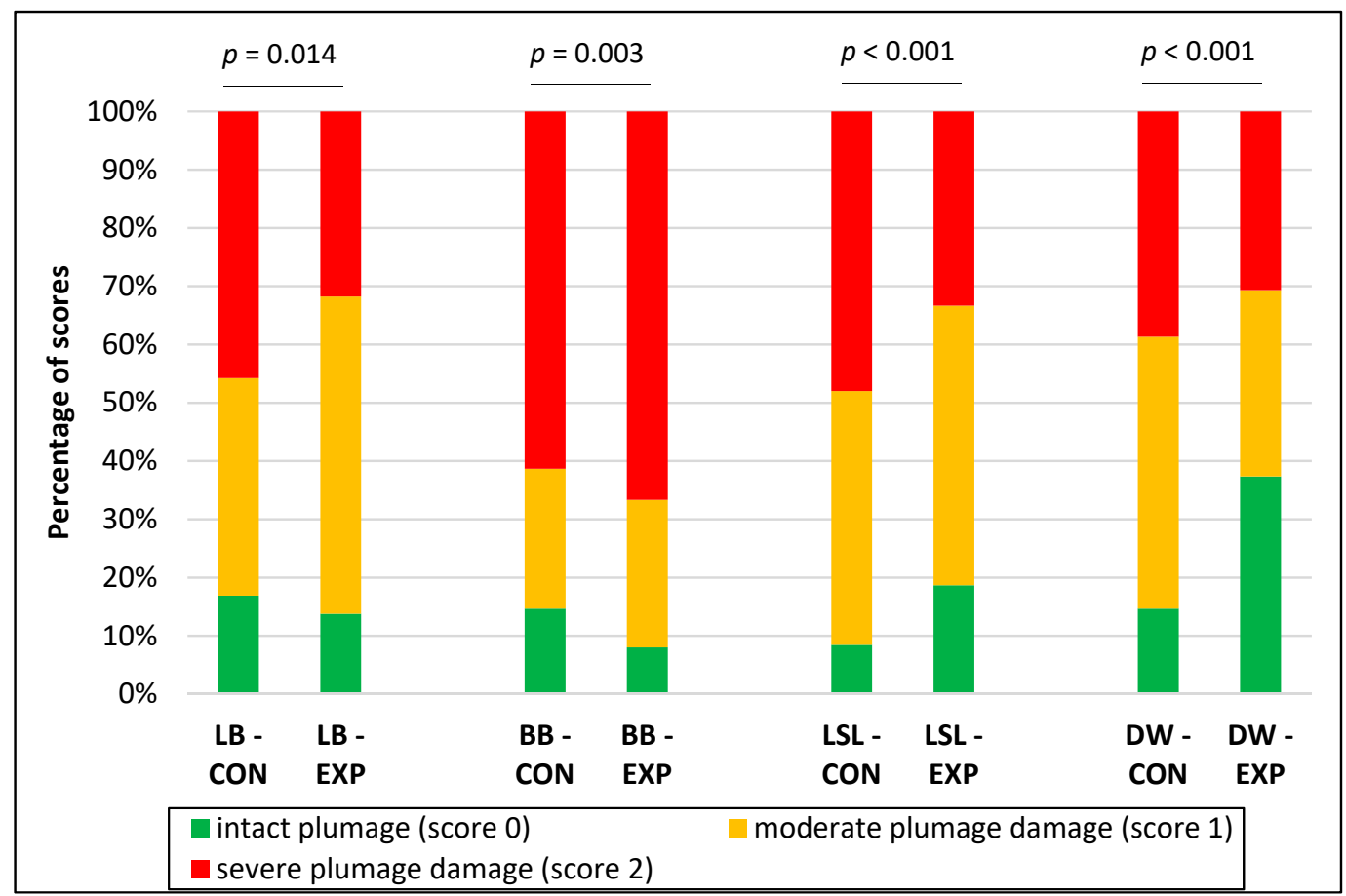

(B)

Figure 2. Effect of strain and supply of edible enrichment materials on plumage condition in weeks 43 (A) and 72 (B). Presented $p$-values refer to the analysis of the total plumage score. LB (CON)-Lohmann Brown classic without supply of enrichment materials; LB (EXP)—Lohmann Brown classic with supply of enrichment materials; BB (CON) - Bovans Brown without supply of enrichment materials; BB (EXP)—Bovans Brown with supply of enrichment materials; LSL (CON) —Lohmann Selected Leghorn classic without supply of enrichment materials; LSL (EXP)_Lohmann Selected Leghorn classic with supply of enrichment materials; DW (CON)—Dekalb White without supply of enrichment materials; DW (EXP)—Dekalb White with supply of enrichment materials.

Toe injuries occurred exclusively in LSL hens in weeks 43 and 72. The prevalence within that strain was higher in the EXP compared to the CON in weeks 43 (CON: $90.7 \%$ score $0,5.3 \%$ score 1 , $4.0 \%$ score 2 ; EXP: $76.0 \%$ score $0,16.0 \%$ score $1,8.0 \%$ score 2$)(p=0.018)$ and 72 (CON: $89.4 \%$ score 0 , 1.3\% score 1, 9.3\% score 2; EXP: 74.7\% score $0,1.3 \%$ score $1,24.0 \%$ score 2$)(p=0.018)$.

Given the partly divergent effects of EM between strains in the univariate analyses, in addition to the effects of strains, groups, and ages on plumage condition and skin lesions, possible strain-group interactions were analyzed in the BLR models (Table 1). With respect to plumage condition, the effects of strains, EM groups, ages, and compartments were observed. Nagelkerke's $\mathrm{R}^{2}$ values showed a very good explanatory quality of the final model for this trait (Nagelkerke's $R^{2}=0.726$ ). An age effect was observed in skin lesions (Nagelkerke's $\mathrm{R}^{2}=0.326$ ). The significant strain-group interactions in both plumage conditions and skin injury models were highlighted. Compared to LB-CON as a basis, the effect of EM provision on plumage condition was different in the BB and DW. In terms of skin lesions, only the BB hens differed from the previously mentioned base (Table 1). 


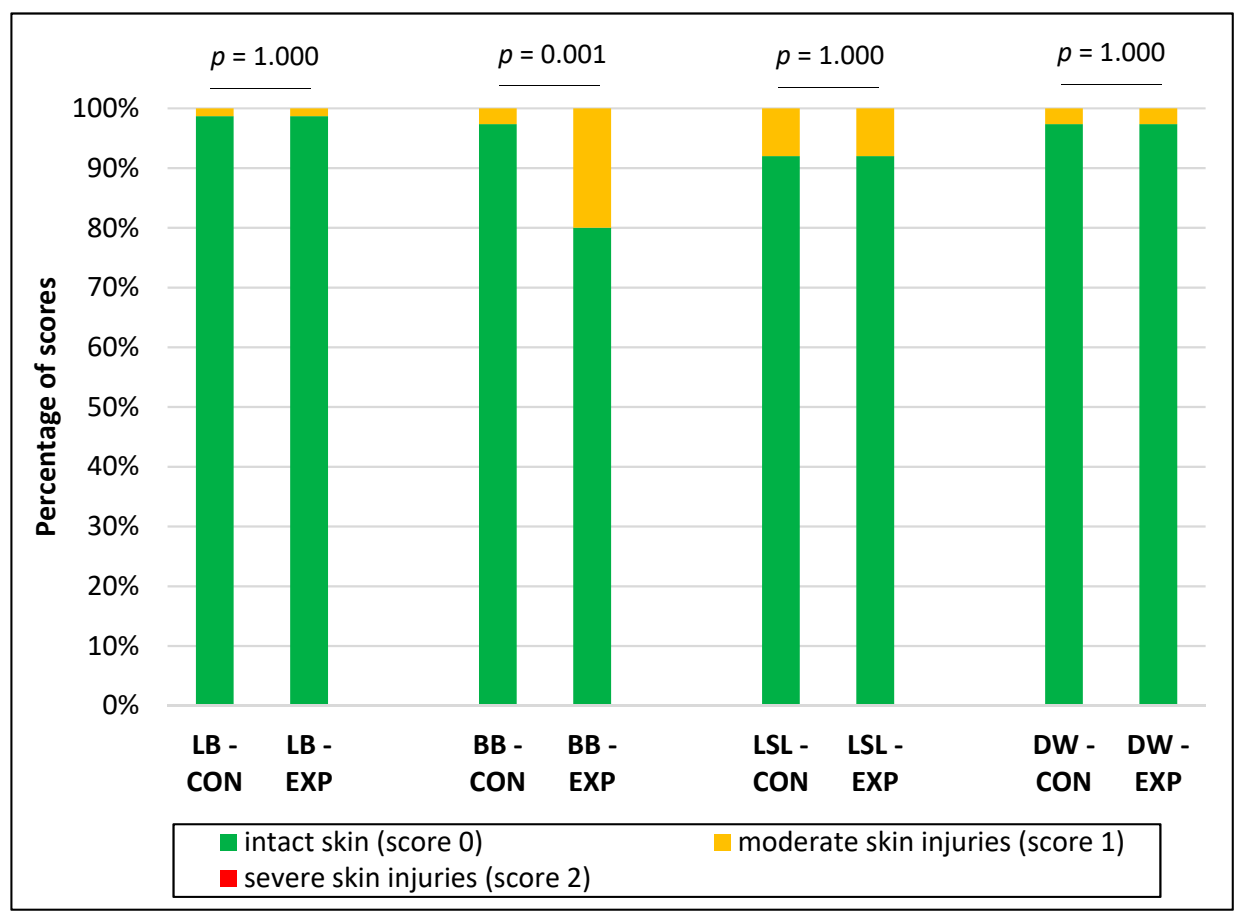

(A)

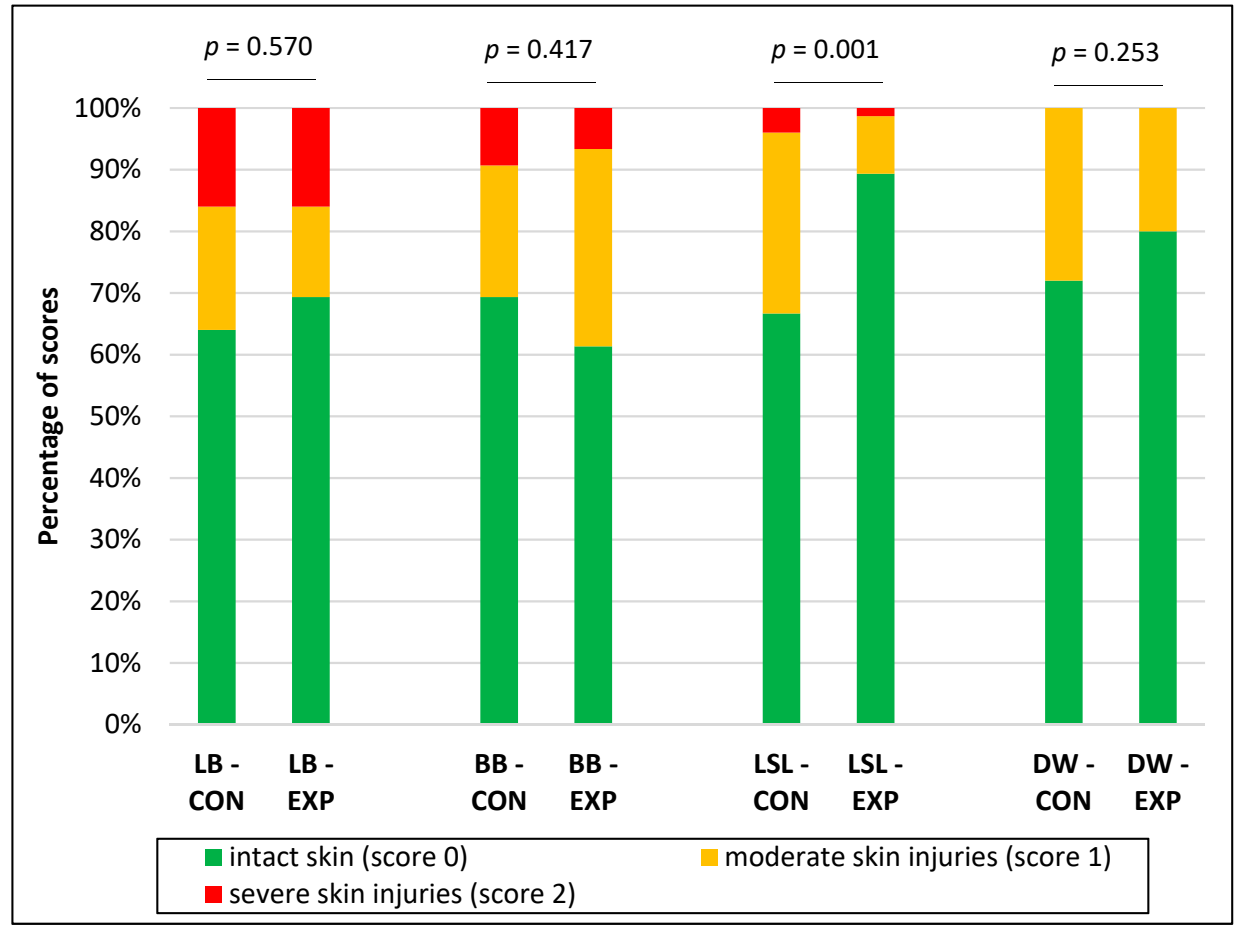

(B)

Figure 3. Effect of strain and supply of edible enrichment materials on skin condition in weeks 43 (A) and 72 (B). LB (CON)-Lohmann Brown classic without supply of enrichment materials; LB (EXP)—Lohmann Brown classic with supply of enrichment materials; BB (CON)—Bovans Brown without supply of enrichment materials; BB (EXP)—Bovans Brown with supply of enrichment materials; LSL (CON)_Lohmann Selected Leghorn classic without supply of enrichment materials; LSL (EXP)—Lohmann Selected Leghorn classic with supply of enrichment materials; DW (CON)—Dekalb White without supply of enrichment materials; DW (EXP)—Dekalb White with supply of enrichment materials. 
Table 1. Effect of strain, age, enrichment group, and interaction strain * enrichment group on integument condition-results of the logistic regression models.

\begin{tabular}{|c|c|c|c|c|c|}
\hline Trait & Score $1(\%)$ & Coefficients (SE) & Odds Ratio (95\% CI) & $\begin{array}{c}\text { Individual } \\
p \text {-Value }\end{array}$ & $\begin{array}{l}\text { Overall } \\
p \text {-Value }\end{array}$ \\
\hline \multicolumn{6}{|c|}{ Total Plumage Score } \\
\hline LB & 45.6 & reference & baseline & & \multirow{4}{*}{$<0.001$} \\
\hline $\mathrm{BB}$ & 52.7 & $-0.74(0.31)$ & $0.48(0.26-0.87)$ & 0.016 & \\
\hline LSL & 46.4 & $0.14(0.31)$ & $1.14(0.63-2.09)$ & 0.662 & \\
\hline DW & 35.6 & $-1.59(0.32)$ & $0.20(0.11-0.38)$ & $<0.001$ & \\
\hline week 20 & 1.3 & reference & baseline & & \multirow{3}{*}{$<0.001$} \\
\hline week 43 & 40.7 & $4.35(0.38)$ & $77.43(36.47-164.36)$ & $<0.001$ & \\
\hline week 72 & 93.2 & $7.69(0.42)$ & $2199.89(963.13-5024.78)$ & $<0.001$ & \\
\hline $\mathrm{CON}$ & 45.2 & reference & baseline & & \multirow[b]{2}{*}{0.001} \\
\hline EXP & 44.9 & $-1.09(0.32)$ & $0.34(0.18-0.63)$ & & \\
\hline compartment & - & $0.04(0.01)$ & $1.04(1.01-1.06)$ & & \multirow[t]{2}{*}{0.003} \\
\hline $\mathrm{CON} \times \mathrm{LB}$ & 49.8 & reference & baseline & & \\
\hline $\mathrm{EXP} \times \mathrm{BB}$ & 61.3 & $3.24(0.49)$ & $25.49(9.79-66.20)$ & $<0.001$ & \multirow{4}{*}{$<0.001$} \\
\hline $\mathrm{EXP} \times \mathrm{LSL}$ & 40.4 & $-0.09(0.44)$ & $0.91(0.38-2.17)$ & 0.838 & \\
\hline $\mathrm{EXP} \times \mathrm{DW}$ & 36.4 & $1.22(0.44)$ & $3.40(1.43-8.09)$ & 0.006 & \\
\hline constant & & $-4.66(0.45)$ & & & \\
\hline \multicolumn{6}{|l|}{ Skin Injuries } \\
\hline $\mathrm{LB}$ & 11.6 & reference & baseline & & \multirow{5}{*}{0.632} \\
\hline $\mathrm{BB}$ & 15.3 & $-0.19(0.32)$ & $0.83(0.44-1.56)$ & 0.560 & \\
\hline LSL & 10.0 & $0.11(0.31)$ & $1.11(0.61-2.06)$ & 0.728 & \\
\hline DW & 8.9 & $-0.26(0.32)$ & $0.77(0.41-1.45)$ & 0.416 & \\
\hline week 20 & 0.0 & reference & baseline & & \\
\hline week 43 & 5.8 & 18.41 (1620.70) & $50.71(0.74-77.51)$ & 0.991 & \multirow[t]{2}{*}{$<0.001$} \\
\hline week 72 & 28.5 & $20.32(1620.70)$ & $1008(0.89-2171.81)$ & 0.990 & \\
\hline $\mathrm{CON}$ & 11.9 & reference & baseline & & \multirow[b]{2}{*}{0.436} \\
\hline EXP & 11.0 & $-0.26(0.33)$ & $0.77(0.40-1.48)$ & & \\
\hline compartment & - & $0.01(0.01)$ & $1.01(0.98-1.04)$ & & 0.527 \\
\hline $\mathrm{CON} \times \mathrm{LB}$ & 12.4 & reference & baseline & & \multirow{5}{*}{0.001} \\
\hline $\mathrm{EXP} \times \mathrm{BB}$ & 19.6 & $1.14(0.47)$ & $3.14(1.24-7.91)$ & 0.016 & \\
\hline $\mathrm{EXP} \times \mathrm{LSL}$ & 6.2 & $-0.74(0.49)$ & $0.48(0.18-1.26)$ & 0.134 & \\
\hline $\mathrm{EXP} \times \mathrm{DW}$ & 7.6 & $-0.13(0.48)$ & $0.87(0.34-2.26)$ & 0.784 & \\
\hline constant & & $-21.20(1620.44)$ & & & \\
\hline
\end{tabular}

interaction strain * enrichment group - statistical interaction between strain and enrichment group, SE-standard error; CI—confidence interval; LB - Lohmann Brown classic; BB—Bovans Brown, LSL-Lohmann Selected Leghorn classic; DW—Dekalb White; CON—control group (without additional enrichment materials); EXP—experimental group (supply of additional enrichment materials); Score 0-intact plumage/skin; Score 1-plumage/skin damage.

\subsection{Body Mass, Performance Traits, EM Consumption and Egg Quality}

During rearing, body mass decreased with the supply of EM $(p<0.001)$ when evaluated over all strains (data not shown). Within the strains, this effect was present for BB (weeks 8 and 16: $p=0.003$ ) and LSL (week 8 and 16: $p=0.002$ ), but not for LB (weeks 8 and 16: $p=0.138$ ) and DW (week 8 and 16: $p=0.233$ ) (Figure 4). A significant interaction between strains and groups did not exist $(p=0.511)$. Uniformity in weeks 8 (CON: $72.8 \pm 7.4 \%$, EXP: $72.8 \pm 6.1 \%)$ and $16(\mathrm{CON}: 86.5 \pm 6.9 \%$, EXP: $88.3 \pm 4.7 \%)$ was not affected by enrichment $(p \geq 0.424)$. Cumulative mortality was $1.6 \%$ (median, minimum-maximum: $0.8-4.4 \%)$ in CON and 1.0\% (0.4-3.6\%) in EXP during rearing ( $p=0.195)$, with no cannibalism-related animal losses. The consumption of pecking stones varied between the strains, with a higher consumption in BB hens $(51.1 \pm 3.6 \mathrm{~g})$ than in LB $(40.3 \pm 2.5 \mathrm{~g})$, LSL $(41.7 \pm 3.5 \mathrm{~g})$ and DW $(37.4 \pm 3.2 \mathrm{~g})(p=0.048)$. During rearing, the hens consumed $29.9 \pm 2.8 \mathrm{~g}$ of alfalfa material, with no differences between the strains $(p=0.101)$.

In the laying period (52 weeks), average hens laid $324.3 \pm 14.9$ eggs, each with an average mass of $62.7 \pm 1.7 \mathrm{~g}$, and required $2.225 \pm 0.110 \mathrm{~kg}$ of feed to produce $1 \mathrm{~kg}$ of egg mass (mean $\pm \mathrm{SD}$ ). 
These performance characteristics differed between the strains $(p<0.001)$, but not between the EXP and $\operatorname{CON}(p \geq 0.582)$.

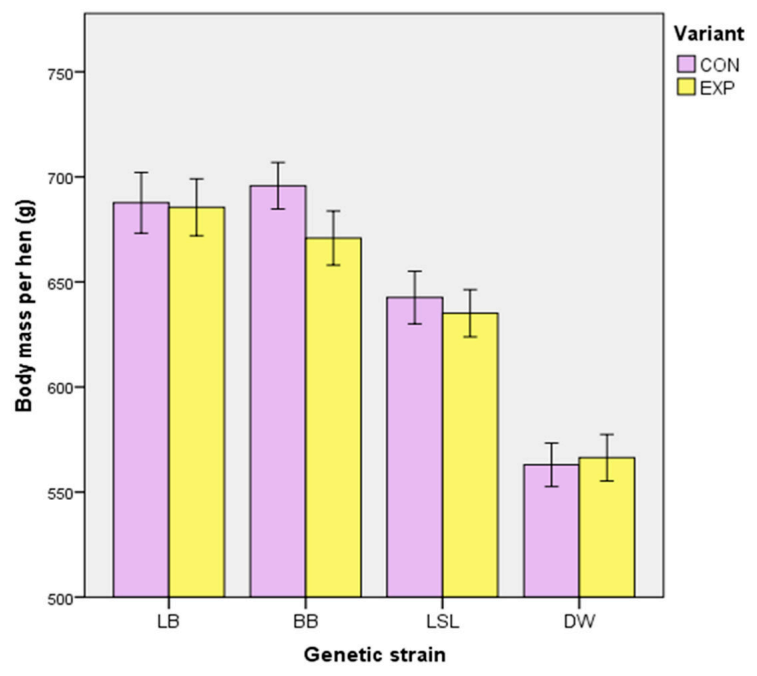

(A)

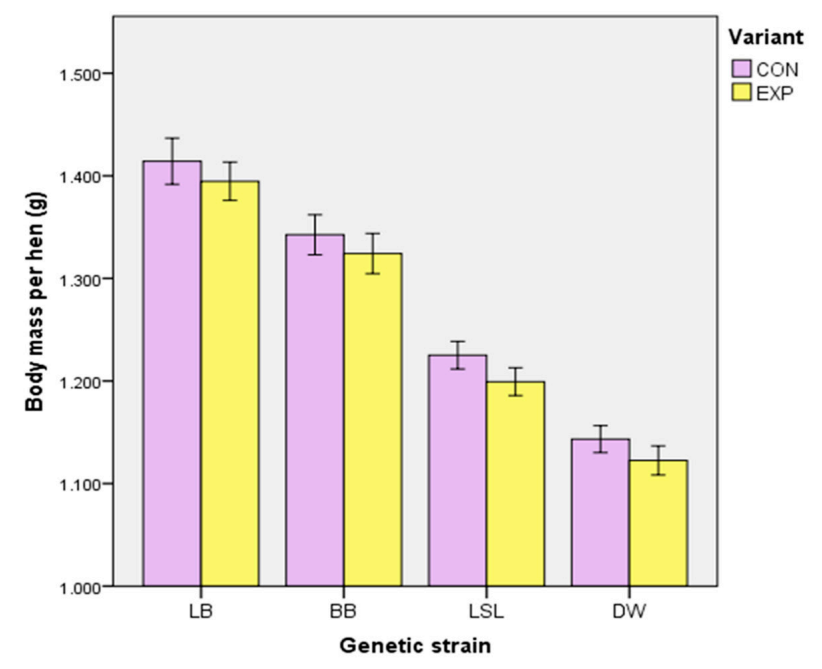

(B)

Figure 4. Effect of edible enrichment materials on body mass in different layer strains during the rearing period in weeks $8(\mathbf{A})$ and $16(\mathbf{B})$. In a repeated-measures ANOVA model, lower body masses were found in BB $(p=0.003)$ and LSL $(p=0.002)$ within EXP compared to CON, but not in LB $(p=0.138)$ and DW ( $p=0.233$ ). CON—control group (without additional enrichment materials); EXP—experimental group (supply of additional enrichment materials); LB = Lohmann Brown classic; BB = Bovans Brown; LSL = Lohmann Selected Leghorn classic; DW = Dekalb White. Error bars represent standard deviation.

The daily feed consumption per hen was not affected by the EM group (CON: $123.3 \pm 2.6$ g; EXP: $124.5 \pm 3.7 \mathrm{~g})(p=0.246)$. In week 72 , body mass differed between the strains $(p<0.001$; LB: $1925 \pm 141$ g, BB: $1912 \pm 134$ g, LSL $1767 \pm 118$ g, DW: $1724 \pm 109$ g), but not between the enrichment groups ( $p=0.963$; CON: $1832 \pm 177 \mathrm{~g}$, EXP: $1834 \pm 181 \mathrm{~g}$ ).

The consumption of alfalfa bales per hen varied between the strains $(p=0.001$; mean $\pm \mathrm{SD}, \mathrm{LB}$ : $256.5 \pm 39.3$ g, BB: $209.5 \pm 21.9$ g, LSL: $131.0 \pm 16.5$ g, DW: $131.8 \pm 16.5$ g), but the pecking stone consumption did not (over all strains: $629 \pm 112.7 \mathrm{~g} ; p=0.353$ ). Cumulative mortality during the laying period was $5.5 \%$ over all strains (median, minimum-maximum: $0.0-24.0 \%$ ), with a lower mortality 
in DW at $1.8 \%(1.6-5.6 \%)$ compared to the other strains, with $6.0 \%$ for LB $(0.0-24.0 \%), 4.1 \%$ for BB $(1.6-9.6 \%)$ and $8.5 \%$ for LSL $(5.5-17.6 \%)(p=0.039)$. EM supply had no effect on cumulative mortality (CON: 5.5\%, 1.6-24.0\%; EXP: 6.4\%, 0.0-17.6\%) ( $p=0.932$ ) and losses due to skin cannibalism (CON: 0.4\%, $0.0-16.8 \%$; EXP: $0.4 \%, 0.0-6.4 \%)(p=0.977)$. Within the strains, cannibalism losses were numerically higher in the CON for LB (CON: 3.6\%, 1.6-16.8\%; EXP: $0.0 \%, 0.0-4.8 \%)(p=0.268)$, but lower in the CON for BB (CON: 0.8\%, 0.0-0.9\%; EXP: 6.3\%, 0.0-6.4\%) ( $p=0.376)$. Animal losses due to toe cannibalism only occurred in LSL $(p<0.001)$. Without a significant effect of EM group, losses due to toe damage were numerically lower in the CON at $0.9 \%(0.9-6.4 \%)$ than in the EXP at $3.8 \%(1.8-12.0 \%)$ $(p=0.268)$.

EM supply had no effect on the breaking strength of the egg shells (week $42-\mathrm{CON}: 45.4 \pm 8.8 \mathrm{~N}$, EXP: $45.1 \pm 8.8 \mathrm{~N}$; week $58-C O N: 41.7 \pm 8.8 \mathrm{~N}$, EXP: $41.0 \pm 8.5 \mathrm{~N}$; week $67-C O N: 39.7 \pm 9.0 \mathrm{~N}$, EXP: $39.6 \pm 9.1 \mathrm{~N})(p=0.765)$. In contrast, access to EM reduced the albumen consistency $(p<0.001)$, with a significant interaction between the strain and group $(p=0.033)$. The albumen consistency was $88.5 \pm 5.4 \mathrm{HU}(\mathrm{CON})$ and $87.4 \pm 5.4 \mathrm{HU}(\mathrm{EXP})$ in week $42,85.4 \pm 5.8 \mathrm{HU}(\mathrm{CON})$ and $84.1 \pm 6.5 \mathrm{HU}(\mathrm{EXP})$ in week 58, and $84.0 \pm 6.3 \mathrm{HU}(\mathrm{CON})$ and $83.0 \pm 7.4 \mathrm{HU}(\mathrm{EXP})$ in week 67 , respectively. Compared to CON, lower HU values were found in the eggs of LB $(p<0.001), \mathrm{BB}(p<0.001)$, and DW $(p=0.027)$ within the EXP, but not in the LSL $(p=0.642)$ (Figure 5).

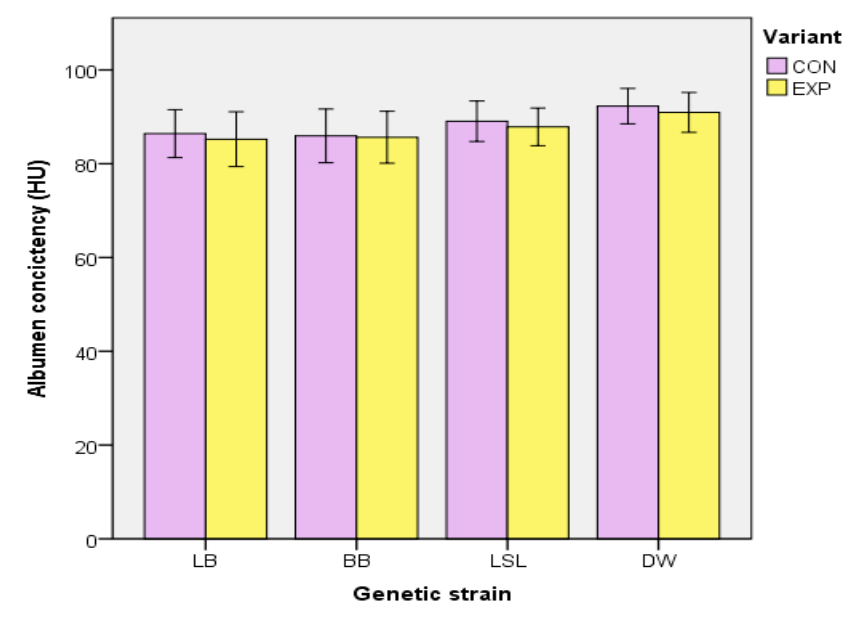

(A)

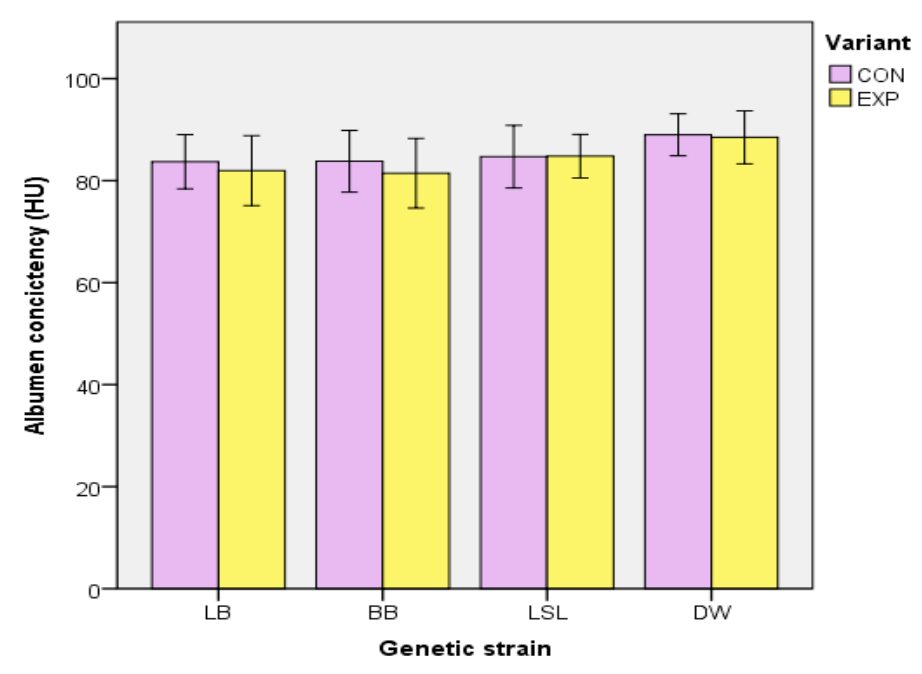

(B)

Figure 5. Cont. 


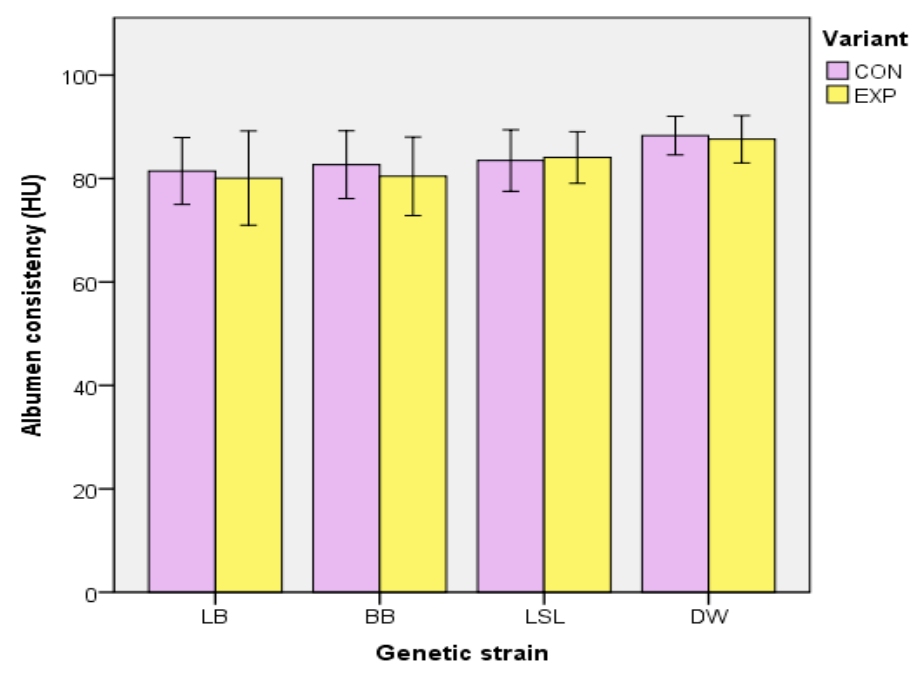

(C)

Figure 5. Effect of edible enrichment materials on albumen consistency in different layer strains in weeks 42 (A), 58 (B), and 67 (C). In a repeated-measures ANOVA model, lower HU values were found in the eggs of LB $(p<0.001), \mathrm{BB}(p<0.001)$, and DW ( $p=0.027)$ within EXP compared to CON, but not in LSL $(p=0.642)$. HU-Haugh Units; CON-control group (without additional enrichment materials) EXP-experimental group (supply of additional enrichment materials); LB = Lohmann Brown classic; $\mathrm{BB}=$ Bovans Brown; LSL = Lohmann Selected Leghorn classic; DW = Dekalb White. Error bars represent standard deviation.

\section{Discussions}

This study investigated the effect of an additional EM supply in littered housing systems on the integument condition and performance of different layer strains. The obtained results regarding integument condition traits provide new insight into several aspects. The positive effects of EM on plumage condition over all strains confirm the results of previous studies [6,26-31]. At the same time, the results are contrary to studies that did not observe such advantages of an EM supply [16,32-34]. Thus far, as the main reason for the inconsistent results between the studies, the different EM materials and their characteristics have been discussed [31]. Furthermore, study-associated differences in the housing and/or management conditions may have triggered these differences. However, the GEI results regarding EM effects revealed in our study indicate that the strains may also contribute to the differing findings. Possible causes for the overall reduction in plumage damage in the groups with pecking stones and alfalfa blocks could include (1) the promotion of foraging and feed intake behavior, which is considered a central factor in avoiding feather pecking [2,5,59]; (2) the fact that the use of pecking stones has an abrasive effect on the beak horn [31], making the protruding beak tip less effective for pecking feathers [60]; and (3) that additional nutrients/active substances ingested with EM reduce the risk of behavioral disorders at the animal nutritional level, as is known to be the case for sodium and crude fibre [61,62].

The EM supply was able to reduce skin lesions in LSL in week 72 but increased the prevalence in BB in week 43. Logistic regression models revealed significant interactions between strain and EM group for skin injuries as well as for plumage damage, which indicated the presence of GEI in these integument traits. Regarding plumage condition, EM had a positive effect in LB and LSL but a negative effect in BB. EXP groups in DW exhibited higher plumage damage in week 43 but lower damage in week 72 in comparison to CON. GEIs outlined as significant interactions between the genetic strain and the housing system were observed by [36-38,63-65] for various performance characteristics, including feed consumption and egg quality. Additionally, the GEIs between layer strains and housing systems for mortality were demonstrated within different brown egg-layer strains [66] and between white- and 
brown egg layers [67]. With the exception of the study by [31], the identification of GEIs in the supply of EM in littered housing systems has not yet been reported, because the majority of previous studies investigated only a single strain $[6,16,26-30,32-34]$. In furnished cages that were enriched with sand or sawdust, behavior and integument-associated interactions were shown by [68]. In Hy-Line White and Hy-Line Brown hens, an interaction between genotype and litter was found for the traits of body mass, claw length, and heterophilic/lymphocyte ratio as a stress indicator, but not in plumage condition and mortality. [69] observed no interaction between the group size and plumage condition of laying hen parent-stock flocks. Moreover, GEIs for the nesting behavior of laying hens are also known [70]. In turkeys, [71] found divergent effects between the sexes in cannibalism-induced animal losses when EM was used. The animal losses due to cannibalism in male turkeys were significantly higher in the groups with EM compared to the control groups, whereas EM had no statistically significant effect on mortality in turkey hens.

Summarizing the results of previous studies, interactions between genotypes and the environment have already been identified in individual behavioral or integument condition traits. With our study, these interactions were extended for an EM supply regarding plumage damage and skin injuries. Differences in the expression of genes relevant for feather pecking could be potential causes of this [72]. Furthermore, the divergent effect in the corticosterone reaction patterns between different laying hen strains after an additional intake of fibrous substrates could also offer an explanation [73]. However, the previously feared suppression of compound feed intake by EM [74] is not a main cause in the present study, as there were no significant differences in daily feed consumption between CON and EXP. The divergent response of the strains to EM access concerning the plumage condition indicates that-in the multifactorial causal structure of feather pecking - the weighting of the individual risk factors may differ between the strains, which should be verified by further studies.

Cannibalism is an important cause of animal loss in laying hens [49], with a high positive correlation between plumage and/or skin damage and the occurrence of cannibalism losses [75]. A significantly higher plumage damage and numerically higher animal losses due to cannibalism were also observed in the LB CON groups in our study. However, significantly lower plumage and skin damage with numerically lower cannibalism losses were observed in the BB CON groups compared to EXP. This underlines the relevance of the observed GEIs. The high animal losses $(>10 \%)$ in 3 of the 24 compartments were mainly due to cannibalism of the skin (LB) and toes (LSL). In the view of the wide range between minimum and maximum in animal losses, the numbers of compartments per variant and runs should be increased in future studies to identify possible effects of EM in that trait.

Toe injuries are indirect indicators of toe pecking, which is a serious problem for animal health and welfare [12]. As in our study, previous investigations found toe injuries primarily in white egg layers $[4,49,76]$. Molecular genetic investigations confirmed their genetic predisposition for toe pecking [11]. In a recent laying hen performance test, however, toe injuries were also identified in DW [49]. For the first time, an increase in the prevalence of toe injuries with an EM supply could be shown in the present study, although final explanations are lacking. However, since the offer of EMs is accompanied by changes in the frequency of the use of certain stable areas [32], we cannot exclude the possibility that the more frequent flying arrival and departure events from equipment elements in EXP increased the risk of technopathic toe injuries. Subsequently, pre-existing toe injuries may trigger toe pecking [11]. Since toe pecking can cause death [77], the numerically higher animal losses due to toe injuries in the LSL EXP groups (3.8\% vs. 0.9\%) seem remarkable.

Hens reared with EM had lower body weights in weeks 8 and 16 compared to the CON, as already shown by [78]. Neither laying performance nor egg mass production increased with access to EM, as confirmed by recent studies [16,30,33,78]. In contrast to this study, [78] found higher egg weights in groups with access to pecking stones and alfalfa bales during the laying period. To our knowledge, no effect of EM provision in littered housing systems on albumen consistency as a trait of internal egg quality has been reported yet. CON eggs showed higher HU values in comparison to EXP. Other studies that examined this context found no unidirectional effect of the EM variant [28,78]. Possible 
nutritional causes for the reduced albumen consistency when EMs are ingested can be discussed. Elsherif et al. [79] found a reduced albumen consistency with the additional intake of copper in compound feed. In our study, pecking stones contained $90 \mathrm{mg} / \mathrm{kg}$ copper, which could explain the observed effect. Furthermore, a significant interaction between strain and EM group was observed for albumen consistency. With the performed study design, it was not possible to explain why EM effects in DW were not analogous to the three other strains. A GEI regarding albumen consistency was also identified by [68] when comparing the white egg-laying strain LSL with the brown egg-laying strain Atak-S kept in cage systems or with organic free-range farming, respectively. These differences in albumen consistency might be of interest for questions concerning the marketing of table eggs.

Overall, an improvement in the plumage and skin condition of laying hens can be achieved by providing additional EM in littered housing systems. However, since the effect of EM on integument condition differs between the strains, an opposite effect may also occur in certain hybrid lines. The identified GEI in integument traits should be investigated further in additional laying hen strains. Moreover, it is recommended to include as many different strains as possible and an increased number of repeats (i.e., compartments per strain and group and runs) in future studies on the effects of EM in pullets and laying hens. Due to distinct differences in integument conditions between the strains and the interaction with the housing environment, a scoring for plumage, skin, and toe condition should be implemented in laying hen performance tests. Finally, in the view of the divergent effects of EM between the strains, practical recommendations for the supply of EM should be strain-specific. In LSL hens, the provision of EM must be considered carefully on a herd-specific basis, since, although improvements in plumage and skin condition can be expected, toe injuries can occur more frequently.

Author Contributions: Conceptualization, R.S. and K.D.; data assessment and formal analysis, R.S. and M.F.; data interpretation, R.S., K.D., and M.F.; writing —original draft preparation, R.S.; writing—review and editing, R.S., K.D., and M.F. All authors have read and agreed to the published version of the manuscript.

Funding: This research received no external funding. This article is funded by the Open Access Publication Fund of Hochschule für Technik und Wirtschaft-Dresden University of Applied Sciences and the Deutsche Forschungsgemeinschaft (DFG, German Research Foundation)-432908064.

Acknowledgments: The authors would like to thank the staff for the care and management of the animals. Special thanks go to the team of the Bavarian Animal Health Service (TGD Bayern e.V.) for performing the vaccinations.

Conflicts of Interest: The authors declare no conflict of interest.

\section{References}

1. Sherwin, C.M.; Richards, G.J.; Nicol, C.J. Comparison of the welfare of layer hens in 4 housing systems in the UK. Br. Poult. Sci. 2010, 51, 488-499. [CrossRef] [PubMed]

2. Damme, K.; Pirchner, F. Genetische Unterschiede in der Befiederung von Legehennen und Beziehungen zu Produktionsmerkmalen. Archiv. Geflügelkunde 1984, 48, 215-222. (In German)

3. Appleby, M.C.; Hughes, B.O. Welfare of laying hens in cages and alternative systems, environmental, physical and behavioural aspects. World's Poult. Sci. J. 1991, 47, 109-128. [CrossRef]

4. Niebuhr, K.; Zaludik, K.; Gruber, B.; Thenmaier, I.; Lugmair, A.; Troxler, J. Epidemiologische Untersuchungen zum Auftreten von Kannibalismus und Federpicken in Alternativen Legehennenhaltungen in Österreich; Endbericht Forschungsprojekt Nr. 1313 ITT 2006; University Vienna: Vienna, Austria, 2006. (In German)

5. Rodenburg, T.B.; van Krimpen, M.M.; de Jong, I.C.; de Haas, E.N.; Kops, M.S.; Riedstra, B.J.; Nordquist, R.E.; Wagenaar, J.P.; Bestman, M.; Nicol, C.J. The prevention and control of feather pecking in laying hens: Identifying the underlying principles. World's Poult. Sci. J. 2013, 69, 361-373. [CrossRef]

6. Liebers, C.J.; Schwarzer, A.; Erhard, E.; Schmidt, P.; Louton, H. The influence of environmental enrichment and stocking density on the plumage and health conditions of laying hen pullets. Poult. Sci. 2019, 98, 2474-2488. [CrossRef] [PubMed]

7. Savory, C. Feather pecking and cannibalism. World's Poult. Sci. J. 1995, 51, 215-219.

8. Bilcik, B.; Keeling, L.J. Changes in feather condition in relation to feather pecking and aggressive behaviour in laying hens. Br. Poult. Sci. 1999, 40, 444-451. [CrossRef] [PubMed] 
9. Spindler, B.; Giersberg, M.F.; Andersson, R.; Kemper, N. Keeping laying hens with untrimmed beaks-A Review of the status quo in practice and science. Züchtungskunde 2016, 88, 475-493.

10. Gentle, M.J.; Hunter, L.N. Physiological and behavioural responses associated with feather removal in Gallus gallus var domesticus. Res. Vet. Sci. 1991, 50, 95-101. [CrossRef]

11. Buitenhuis, A.J.; Rodenburg, T.B.; Siwek, M.; Cornelissen, S.J.B.; Niewland, M.G.B.; Crooijmans, R.P.M.A.; Groenen, M.A.M.; Koene, P.; Bovenhuis, H.; van der Poel, J.J. Identification of quantitative trait loci for receiving pecks in young and adult laying hens. Poult. Sci. 2003, 82, 1661-1667. [CrossRef]

12. Krause, E.T.; Petow, S.; Kjaer, J.B. A note on the physiological and behavioural consequences of cannibalistic toe pecking in laying hens (Gallus gallus domesticus). Archiv. Geflügelkunde 2011, 75, 140-143.

13. Gebhardt, S. Untersuchung des ZTHZ zum Auftreten von Zehenpicken bei weissen Legehybriden. Schweiz. Geflügelzeitung 2020, 5, 14-15. (In German)

14. Damme, K. Effect of beak-trimming and strain on performance, feather loss and nesting behaviour of different commercial white layer hybrids in floor pens. Archiv. Geflügelkunde 1999, 63, 93-99.

15. Sun, Y.; Ellen, E.D.; van der Poel, J.J.; Parmentier, H.K.; Bijma, P. Modelling of feather pecking behavior in beaktrimmed and non-beak-trimmed crossbred laying hens: Variance component and trait-based approach. Poult. Sci. 2014, 93, 773-783. [CrossRef]

16. Hartcher, K.M.; Tran, K.T.N.; Wilkinson, S.J.; Hemsworth, P.H.; Thomson, P.C.; Cronin, G.M. The effects of environmental enrichment and beak-trimming during the rearing period on subsequent feather damage due to feather-pecking in laying hens. Poult. Sci. 2015, 94, 852-859. [CrossRef]

17. Sepeur, S.; Spindler, B.; Schulze-Bisping, M.; Habig, C.; Andersson, R.; Beyerbach, M.; Kemper, N. Comparison of plumage condition of laying hens with intact and trimmed beaks kept on commercial farms. Eur. Poult. Sci. 2015, 79. [CrossRef]

18. Weeks, C.A.; Lambton, S.; Williams, A.G. Implications for Welfare, Productivity and Sustainability of the Variation in Reported Levels of Mortality for Laying Hen Flocks Kept in Different Housing Systems: A Meta-Analysis of Ten Studies. PLoS ONE 2016, 11, e0146394. [CrossRef]

19. Van Krimpen, M.; Kwakkel, R.; Reuvekamp, B.; van der Peet-Schwering, C.; den Hartog, L.; Verstegen, M. Impact of feeding management on feather pecking in laying hens. World's Poult. Sci. J. 2005, 61, 663-686.

20. Kjaer, J.B.; Bessei, W. The interrelationships of nutrition and feather pecking in the domestic fowl-A review. Archiv. Geflügelkunde 2013, 77, 1-9.

21. Janczak, A.M.; Riber, A.B. Review of rearing-related factors affecting the welfare of laying hens. Poult. Sci. 2015, 94, 1454-1469. [CrossRef]

22. Bessei, W.; Lutz, V.; Kjaer, J.B.; Grashorn, M.; Bennewitz, J. Relationships between foraging and open-field activity in young chicks and feather pecking in adult birds: Results of analyses using quantitative genetics and structural equation models. Eur. Poult. Sci. 2018, 82. [CrossRef]

23. Wennrich, G. Studie zum Verhalten verschiedener Hybrid-Herkünfte von Haushühnern (Gallus domesticus) in Boden-Intensivhaltung mit besonderer Berücksichtigung aggressiven Verhaltens sowie des Federpickens und des Kannibalismus. Archiv. Geflügelkunde 1975, 39, 37-44. (In German)

24. Blokhuis, H.J. Feather pecking in poultry: Its relation with ground pecking. Appl. Anim. Behav. Sci. 1986, 16, 63-67. [CrossRef]

25. Schreiter, R.; Damme, K.; von Borell, E.; Vogt, I.; Klunker, M.; Freick, M. Effects of litter and additional enrichment elements on the occurrence of feather pecking in pullets and laying hens-A focused review. Vet. Med. Sci. 2019, 5, 500-507. [CrossRef] [PubMed]

26. Blokhuis, H.J.; van der Haar, J.W. Effects of pecking incentives during rearing on feather pecking of laying hens. Br. Poult. Sci. 1992, 33, 17-24. [CrossRef]

27. Norgaard-Nielsen, G.; Vestergaard, K.; Simonsen, H.B. Effects of rearing experience and stimulus enrichment on feather damage in laying hens. Appl. Anim. Behav. Sci. 1993, 38, 345-352. [CrossRef]

28. Bari, M.S.; Cohen-Barnhouse, A.M.; Camphell, D.L.M. Early rearing enrichments influenced nest use and egg quality in free-range laying hens. Animal 2020, 14, 1249-1257. [CrossRef] [PubMed]

29. McAdie, T.M.; Keeling, L.J.; Blokhuis, H.J.; Jones, R.B. Reduction in feather pecking and improvement of feather condition with the presentation of a string device to chickens. Appl. Anim. Behav. Sci. 2005, 93, 67-80. [CrossRef] 
30. Steenfeldt, S.; Kjaer, J.B.; Engberg, R.M. Effect of feeding silages or carrots as supplements to laying hens on production performance, nutrient digestibility, gut structure, gut microflora and feather pecking behaviour. Br. Poult. Sci. 2007, 48, 454-468. [CrossRef]

31. Schreiter, R.; Damme, K.; Klunker, M.; Raoult, C.; von Borell, E.; Freick, M. Effects of edible environmental enrichments during the rearing and laying periods in a littered aviary-Part 1: Integument condition in pullets and laying hens. Poult. Sci. 2020, 99, 5184-5196. [CrossRef]

32. Freytag, S.; Kemper, N.; Spindler, B. Einfluss des Zugangs zu Beschäftigungsmaterial Auf Das Verhalten und Die Herdengesundheit von Jung- und Legehennen in Praxisbetrieben-Abschlussbericht. Institut Für Tierhygiene, Tierschutz und Nutztierethologie, Stiftung Tierärztliche Hochschule Hannover. 2016. Available online: https:/www.google.de/url?sa=t\&rct=j\&q=\&esrc=s\&source=web\&cd=1\& ved=2ahUKEwi0sJ_XnfXhAhWKUBUIHSsNAvIQFjAAegQIAhAC\&url=https\%3A\%2F\%2Fwww.ml. niedersachsen.de\%2Fdownload\%2F107762\%2FAbschlussbericht_TiHo_-_Ausstieg_Schnabelkuerzung Einfluss_des_Zugangs_zu_Beschaeftigungsmaterial.pdf\&usg=AOvVaw08urgjDm7zz5ID6F87tKel (accessed on 1 August 2020). (In German)

33. Cronin, G.M.; Hopcroft, R.L.; Groves, P.J.; Hall, E.J.S.; Phalen, D.N.; Hemsworth, P.H. Why did severe feather pecking and cannibalism outbreaks occur? An unintended case study while investigating the effects of forage and stress on pullets during rearing. Poult. Sci. 2018, 97, 1484-1502. [CrossRef] [PubMed]

34. Iqbal, Z.; Drake, K.; Swick, R.A.; Taylor, P.S.; Perez-Maldonado, R.A.; Ruhnke, I. Effect of pecking stones and age on feather cover, hen mortality, and performance in free-range laying hens. Poult. Sci. 2020, 99, 2307-2314. [PubMed]

35. Lüke, F.; Schmitten, F.; Trappmann, W. Die Leistungen von Legehennen verschiedener Herkünfte bei unterschiedlichen Haltungs- und Fütterungsbedingungen. Archiv. Geflügelkunde 1975, 39, 138-142. (In German)

36. Flock, D.K.; Heil, G. A long-term analysis of time trends in the performance profile of white-egg and brownegg hybrid laying strains based on results of official German random sample tests from 1974/75 to 1997/99. Archiv. Geflügelkunde 2002, 66, 1-20.

37. Damme, K.; Simon, I.; Flock, D.K. Adaptability of Laying Hens to Different Environments: Analysis of German Random Sample Tests 2010/11 with floor management and enriched cages. Lohmann Inf. 2012, 47, 9-14.

38. Schreiter, R.; Damme, K.; Simon, I. Random Sample Test in terms of performance and economics of various laying hen hybrids in Germany 2016-2017. Eur. Poult. Sci. 2018, 82. [CrossRef]

39. Lohmann Tierzucht GmbH. Management Guide Alternative Haltung. 2017. Available online: https: //www.ltz.de/de/downloads/management-guides.php (accessed on 1 August 2020).

40. Council Directive 1999/74/EC of 19 July 1999 Laying down Minimum Standards for the Protection of Laying Hens. Available online: http://www.legislation.gov.uk/eudr/1999/74/contents (accessed on 1 August 2020).

41. TierschG. Tierschutzgesetz in der Fassung der Bekanntmachung vom 18. Mai 2006 (BGBl. I S. 1206, 1313), das Zuletzt Durch Artikel 4 Absatz 8 des Gesetzes vom 18. Juli 2016 (BGBl. I S. 1666) Geändert Worden ist. Available online: http://www.gesetze-im-internet.de/tierschg/TierSchG.pdf (accessed on 1 August 2020). (In German)

42. TierSchNutztV. Verordnung zum Schutz Landwirtschaftlicher Nutztiere und Anderer zur Erzeugung Tierischer Produkte Gehaltener Tiere bei Ihrer Haltung.-Tierschutz-Nutztierhaltungsverordnung in der Fassung der Bekanntmachung vom 22. August 2006, BGBl.I, 2043, die Durch Artikel 3 Absatz 2 des Gesetzes vom 30. Juni 2017 (BGBL I, 2147) Geändert Worden ist. Available online: http://www.gesetze-im-internet.de/ tierschnutztv/ (accessed on 1 August 2020). (In German)

43. American Dairy Science Association. Guide for the Care and Use of Agricultural Animals in Research and Teaching. 2010. Available online: https://www.asas.org/docs/default-source/default-document-library/ag guide_3rded.pdf?sfvrsn=4 (accessed on 1 August 2020).

44. Council Directive 2010/63/EU of the European Parliament and of the Council of 22 September 2010 on the Protection of Animals Used for Scientific Purposes. Official, J. 2010, L 276, (October 10). 33. Available online: http://eur-lex.europa.eu/legal-content/DE/TXT/PDF/?uri=CELEX:32010L0063\&from=en (accessed on 1 August 2020).

45. Institute for Medical Statistics and Bioinformatics at the University of Cologne: Webtool Sample Size. Available online: https://imsiewebarchiv.uni-koeln.de/beratung/rechner/b2.html (accessed on 1 August 2020). 
46. Welfare Quality. Welfare Quality Assessment Protocol for Poultry (Broilers, Laying Hens); Welfare Quality Consortium: Lelystad, The Netherlands, 2009.

47. Keppler, C. Managementtool Beurteilungskarten—Legehennen. Anleitung zur Beurteilung des Tierzustandes. University Kassel. 2017. Available online: https://www.mud-tierschutz.de/fileadmin/user_upload/2017-0822_Beurteilungskarten_Legehennen_web.pdf (accessed on 1 August 2020).

48. Jeroch, H.; Müller, R. Nutritional recommendations for laying hens including the rearing period. In Geflügeljahrbuch 2019; Damme, K., Mayer, A., Eds.; Ulmer: Stuttgart, Germany, 2018; pp. 201-227.

49. Damme, K.; Schreiter, R.; Schneider, M.; Hildebrand, R.A. 13. Bayerischer Herkunftsvergleich von Legehybriden in Bodenhaltung. 2018. Available online: https:/www.lfl.bayern.de/mam/cms07/lvfz/ kitzingen/dateien/13._bayerischer_herkunftsvergleich.pdf (accessed on 1 August 2020). (In German).

50. Haugh, R. The Haugh unit for measuring egg quality. US Egg Poult. Mag. 1937, 43, 552-555.

51. Weiß, C. Basic Knowledge of Medical Statistics, 1st ed.; Springer: Berlin/Heidelberg, Germany, 1999; pp. 98-256.

52. Du Prel, J.-B.; Röhrig, B.; Hommel, G.; Blettner, M. Auswahl statistischer Testverfahren. Dtsch. Aerztebl. Int. 2010, 107, 343-348. (In German)

53. Rasch, B.; Friese, M.; Hofmann, W.J.; Naumann, E. Quantitative Methods_Volume 2, 3th ed.; Springer: Heidelberg, Germany, 2010; pp. 55-98.

54. Victor, A.; Elsäßer, A.; Hommel, G.; Blettner, M. Wie bewertet man die p-Wert-Flut? Dtsch. Aerztebl. Int. 2010, 107, 50-56. (In German)

55. Baltes-Götz, B. Logistische Regressionsanalyse Mit SPSS. 2000. Available online: https://www.uni-trier.de/ fileadmin/urt/doku/logist/logist.pdf (accessed on 1 August 2020). (In German)

56. Menard, S. Applied Logistic Regression Analysis, 2nd ed.; Sage: Thousand Oaks, CA, USA, 2002; pp. 41-101.

57. Field, A. Discovering Statistics Using IBM SPSS Statistics, 4th ed.; Sage: Thousand Oaks, CA, USA, 2013; pp. 293-356.

58. Backhaus, K.; Erichson, B.; Plinke, W.; Weiber, R. Multivariate Analysemethoden, 14th ed.; Springer: Berlin, Germany, 2016; pp. 283-356. (In German)

59. Huber-Eicher, B.; Wechsler, B. Feather pecking in domestic chicks: Its relation to dustbathing and foraging. Anim. Behav. 1997, 54, 757-768. [CrossRef]

60. Icken, W.; Cavero, D.; Schmutz, M. Selection on beak shape to reduce feather pecking in laying hens. Lohmann Inf. 2017, 51, 22-27.

61. Cooke, B.C. Cannibalism in laying hens. Vet. Rec. 1992, 131, 495. [CrossRef] [PubMed]

62. Van Krimpen, M.M.; Kwakkel, R.P.; van der Peet-Schwering, C.M.; den Hartog, L.A.; Verstegen, M.W. Low dietary energy concentration, high nonstarch polysaccharide concentration, and coarse particle sizes of nonstarch polysaccharides affect the behavior of feather-pecking-prone laying hens. Poult. Sci. 2008, 87, 485-496. [CrossRef] [PubMed]

63. Muir, W.M. Relative efficiency of selection for performance of birds housed in colony cages based on performance in single bird cages. Poult. Sci. 1985, 64, 2239-2247. [CrossRef]

64. Leyendecker, M.; Hamann, H.; Hartung, J.; Kamphues, J.; Ring, C.; Glünder, G.; Ahlers, C.; Sander, I.; Neumann, U.; Distl, O. Analysis of genotype-environment interactions between layer lines and housing systems for performance trails, egg quality and bone strength. 2nd communication: Egg quality traits. Züchtungskunde 2001, 73, 308-323.

65. Ledvinka, Z.; Tůmová, E.; Englmaierová, M.; Podsedníček, M. Egg quality of three laying hen genotypes kept in conventional cages and on litter. Archiv. Geflügelkunde 2016, 76, 38-43.

66. Yakubu, A.; Salako, A.E.; Ige, A.O. Effects of Genotype and Housing System on the Laying Performance of Chickens in Different Seasons in the Semi-Humid Tropics. Int. J. Poult. Sci. 2007, 6, 434-439. [CrossRef]

67. Küçükyılmaz, K.; Bozkurt, M.; nur Herken, E.; Çınar, M.; Uğur Çatlı, A.; Bintaş, E.; Çöven, F. Effects of Rearing Systems on Performance, Egg Characteristics and Immune Response in Two Layer Hen Genotype. Asian-Aust. J. Anim. Sci. 2012, 25, 559-568.

68. Wall, H.; Tauson, R.; Elwinger, K. Effects of Litter Substrate and Genotype on Layers' Use of Litter, Exterior Appearance, and Heterophil: Lymphocyte Ratios in Furnished Cages. Poult. Sci. 2008, 87, 2458-2465. [CrossRef]

69. De Haas, E.N.; Kemp, B.; Bollhuis, J.E.; Groothuis, T.; Rodenburg, T.B. Fear, stress, and feather pecking in commercial white and brown laying hen parent-stock flocks and their relationships with production parameters. Poult. Sci. 2013, 92, 2259-2269. [CrossRef] 
70. Purdum, S.; Eusebio, P.; Hanford, K. The effects of 2 genetic lines on spatial distribution and use and preference of perch and nest area in an aviary system. Poult. Sci. 2020, 99, 3328-3333. [CrossRef] [PubMed]

71. Berk, J.; Stehle, E.; Bartels, T. Haltung schnabelunbehandelter Puten-Beschäftigung hält nicht immer vom Picken ab. DGS-Magazin 2016, 39, 35-38. (In German)

72. Falker-Gieske, C.; Mott, A.; Preuß, S.; Franzenburg, S.; Bessei, W.; Bennewitz, J.; Tentens, J. Analysis of the brain transcriptome in lines of laying hens divergently selected for feather pecking. BMC Genom. 2020, 21, 595. [CrossRef] [PubMed]

73. Alm, M.; Holm, L.; Tauson, R.; Wall, H. Corticosterone metabolites in laying hen droppings-Effects of fiber enrichment, genotype, and daily variations. Poult. Sci. 2014, 93, 2615-2621. [CrossRef] [PubMed]

74. Schreiter, R.; Damme, K. Nutrition of Laying Hens-Use of Domestic Feed and Feeding of Laying Hens with Untrimmed Beaks; Bavarian Institute for Agriculture: Freising, Germany, 2017; Available online: www.baysg. bayern.de/mam/cms16/zentren/kitzingen/dateien/legehennenfuetterung_baysg-publikation.pdf (accessed on 1 August 2020).

75. Kjaer, J.B.; Sorensen, P. Feather pecking and cannibalism in free-range laying hens as affected by genotype, dietary level of methionine + cystine, light intensity during rearing and age at first access to the range area. Appl. Anim. Behav. Sci. 2002, 76, 21-39. [CrossRef]

76. Schreiter, R.; Damme, K.; Hartmann, J.; Klunker, M.; Freick, M.; Wolff, N.; von Borell, E. Effect of a specially to reduce feather pecking designed feed on the performance and the occurrence of behavioural disorders in laying hens. Eur. Poult. Sci. 2019, 83. [CrossRef]

77. Craig, J.V.; Lee, H.Y. Beak Trimming and Genetic Stock Effects on Behavior and Mortality from Cannibalism in White Leghorn-Type Pullets. Appl. Anim. Behav. Sci. 1990, 25, 107-123. [CrossRef]

78. Schreiter, R.; Damme, K.; Klunker, M.; Raoult, C.; von Borell, E.; Freick, M. Effects of edible environmental enrichment during the rearing and laying period in a littered aviary-Part 2: Physical development of pullets and performance, egg quality and carcase composition in laying hens. Poult. Sci. 2020, 99, 6685-6696. [CrossRef]

79. Elsherif, H.; Foaud, A.; Nassar, S.; Wahba, F.; Elsabagh, M.; ElIraqi, K. Effect of dietary copper sulphate on laying hen performance, egg quality, and oxidative stress in hot climate conditions. Eur. Poult. Sci. 2019, 83. [CrossRef]

Publisher's Note: MDPI stays neutral with regard to jurisdictional claims in published maps and institutional affiliations.

(C) 2020 by the authors. Licensee MDPI, Basel, Switzerland. This article is an open access article distributed under the terms and conditions of the Creative Commons Attribution (CC BY) license (http://creativecommons.org/licenses/by/4.0/). 